\title{
Analyzing Translation Strategies Utilized in the Translation of Song "Do You Want to Build a Snowman?"
}

\author{
Chrisna Leni \& Athriyana Santye Pattiwael \\ chrisnalenii@gmail.com \& athriyana.pattiwael@ukrida.ac.id \\ Faculty of Humanities and Social Sciences, Universitas Kristen Krida Wacana
}

\begin{abstract}
This study focuses on revealing translation strategies used in the translation of song "Do you want to build a snowman?" in terms of strategic and non-strategic translation strategies. The data were the lines of a pair English-Indonesian selected song lyrics. The analysis of non-strategic translation strategies and strategic translation strategies was conducted by basing on the framework developed by Åkerström (2009) and Lefevere (1975). This study used qualitative descriptive method in analyzing the data. The result of the study shows that the translator tends to translate lines of the lyrics by using fewer number of words, yet the number of syllables remains similar to the source lines. Regarding strategic translation strategies used by the translator in translating lines of the lyrics, it is found that five strategies out of nine strategies have been used, they are paraphrases, rhymes, interpretation, omission of words, and addition of words strategies.
\end{abstract}

Keywords: Non-Strategic translation strategies, song translation, strategic translation strategies

\section{Introduction}

Translation has become a common strategy used by people in daily life, considering that different country tends to have different languages. Therefore, translation aims at facilitating and bridging the differences among languages. Translation activity is needed in various fields such as entertainment, law, medical, and also education. One of the form of translation is song translation. Song translation is provided in order to help the listeners who have different languages not only enjoying the rhythm of the music, but also supporting them to understand the meaning of those foreign song lyrics.

Song translation is a challenging process because the translators' tasks are not only rendering the meaning of the original lyrics but they are also demanded to pay attention on the other demands when creating the translated version of the song, which is the rhythm of the music (Stephenson, 2014). The translators of song consequently have to deal with the meaning of the lyrics as well as the rhythm of the music by having a careful consideration on the word choices. They need to ensure that the words are not only covered the source message but also have similar or closely similar number of syllables to the source lyrics in order to have a singable song translation.

Another challenging situation arises when the target listeners are children. It happens because children are considered as special audience who have limited experience and knowledge of vocabulary compared with adults (Rurangwa, 2006). Children might find difficuties in comprehending words that are unfamiliar for them or words that are rarely used in their daily conversation. The 
translators are then directed to pay more attention on the level of children understanding when translating song lyrics that are intended to be heard by children as the target listeners because children have their own capacity in understanding the lyrics (Stolze, 2003).

Translating song lyrics from English to Indonesian is an interesting topic to be scrutinized since both countries have different languages. The translators of songs then have to ensure that the message covered by the source lyrics can be delivered into the target lyrics and also can be made into a singable song lyrics. This dynamic spurs the researcher to conduct this study to capture the process behind the translation of one Disney's popular song entitled "Do you want to build a snowman?" by identifying the non-strategic translation strategies in order to know the singability of the lyrics to the music and also the strategic translation strategies which refer to the strategies used by the translator to translate the lyrics by basing on the theory of song translation developed by Åkerström (2009) and Lefevere (1975).

Åkerström (2009) proposes ten translation strategies in dealing with song lyrics translation which are divided into two different sub-parts, they are non-strategic translation strategies and strategic translation strategies. The non-strategic translation strategies proposed by Åkerström (2009) consist of two categories, namely word count and syllables vs. words. In revealing the strategic translation strategies used by the translator to translate the lyrics, this study combined Åkerström (2009) and Lefevere's (1975) theories. There are nine of them in total, namely word for word translation, addition of words, omission of words, use of metaphors, use of rhymes, use of paraphrases, use of English words in the translation, literal translation and interpretation strategy (Åkerström, 2009; Lefevere, 1975, cited in Aji, 2016).

Furthermore, there are five criteria that should be considered by the translators when producing song translation, namely singability, sense, naturalness, rhythm, and rhyme (Low,
2005, cited in Siitonen, 2014). The translators of songs need to retain a balance between those five criteria and not emphasize any of them particularly in order to find a successful translation result for the song translation.

In dealing with song translation, Franzon (2008) also suggests five number of choices that a song translator may have when translating song lyrics. The first option is the translator may leave the song untranslated if it is found that there are spoken dialogues included in part of the song. Translating the lyrics but not taking the music into account is known as the second option. It is applied when the translator tends to focus only on the meaning of the lyrics.

Another option is writing new lyrics to the original music because the translator might take the music of the song as the most important aspect to the translation. The next option is the translator is adapting the music to the translation in order to preserve the meaning. Adapting the translation to the original music is the last option. The translator modifies the translation of the source lyrics as function to produce target lyrics that followed the original music of the song.

The process behind song translation has been viewed and analyzed from many different perspectives. Aji (2016) conducted a study on song translation analysis, in which he randomly chose five translated English Disney's songs to Indonesian. In analyzing the translation strategies, the framework of his study was based on Lefevere's (1975) theory.

Aji found that 5 strategies out of 7 strategies were found to be used by the translator. Blank verse translation is the most frequently strategies used in translating those five selected songs. It was commonly used because the translators tend to focus on transferring the meaning of the source lyrics to the target lyrics, while at the same time they tend to ignore the rhyme.

Maulana also conducted a study (2016) on the translation strategies that used in translating Indonesian song lyrics to English. She aimed at identifying what translation 
strategies used to translate the lyrics by using Åkerström's (2009) theory as the framework of her study. In her findings, Maulana found out that there were five strategies used by the translator to translate the song lyrics. The most frequently used strategy in translating song lyrics is the use of paraphrase. This strategy is used in order to deliver the meaning of the lyrics clearly.

Associating with the issues in translating song lyrics that are intended to be heard by children as the target listeners, Klingberg (1986) suggests that adaptation can be applied as a particular method in translating for children. It is necessary to be applied by the translator in order to give the opportunity for children to understand the lyrics better. The adaptation can be done by transferring an expression that is presented in the source lyrics with a similar function to the target lyrics (Klingberg, 1986).

\section{Methodology}

This study was classified as a primary research because the data were directly taken from the collection of Disney's song lyrics by the researcher. This study used qualitative descriptive method in analyzing the data. This method is in line with the idea expressed by Fraenkel and Wallen (1993) that "Descriptive method is a method used to explain, analyze, and classify something through various strategies and survey". It is suitable for this study because the data were organized in a logical manner in order to provide a detailed and clearer explanation related to the findings.

The data used in this study were the group of words in each line of Disney's song lyrics taken from a Disney animated feature film Frozen, entitled "Do you want to build a snowman?" and its translated version in Indonesian, entitled "Yuk buat boneka salju". The source lines and target lines of the lyrics were aligned side by side in a table by using Microsoft Word in order to ease the analysis process.

\section{Findings}

\section{Non-Strategic Translation Strategies}

Non-strategic translation strategies in song Do you want to build a snowman? which refer to the line structure of the lyrics are identified by using the theory of translation strategies proposed by Åkerström in 2009. The analysis under this strategy is divided into two categories namely word count and syllables vs words. The analysis are presented and discussed in the following sections.

\section{Word Count Analysis}

Word count is a strategy that refers to a comparison of the number of words in the source line and the target line of song lyrics (Åkerström, 2009). The selected Disney's song Do you want to build a snowman? contains 26 lines from the lyrics. It was found that the number of words in the target lines are fewer than the source lines. The summary of word count analysis in song Do you want to build a snowman? along with its translated version is presented in Figure 1.

The analysis of word count in line of the song lyric is presented and discussed in the following selected example.

\begin{tabular}{c|l|l} 
(1) Line & SL: I wish you & TL: Jelaskanlah \\
9 & would tell me & mengapa! \\
& (7 words) & (2 words)
\end{tabular}

The example of word count analysis is taken from the selected line shows that a significant decrease of word number appears in this target Line 9. It is found that the total number of words in this source Line 9 is almost four times longer compared to the target line, as the source line has seven words and the target line only has two words. This fewer words might be related to translator's decision to maintain the central meaning of the source line, which is "expressing a request for sharing explanation", at the expense of changing the form in the target line. 
Figure 1. The Summary of Word Count Analysis

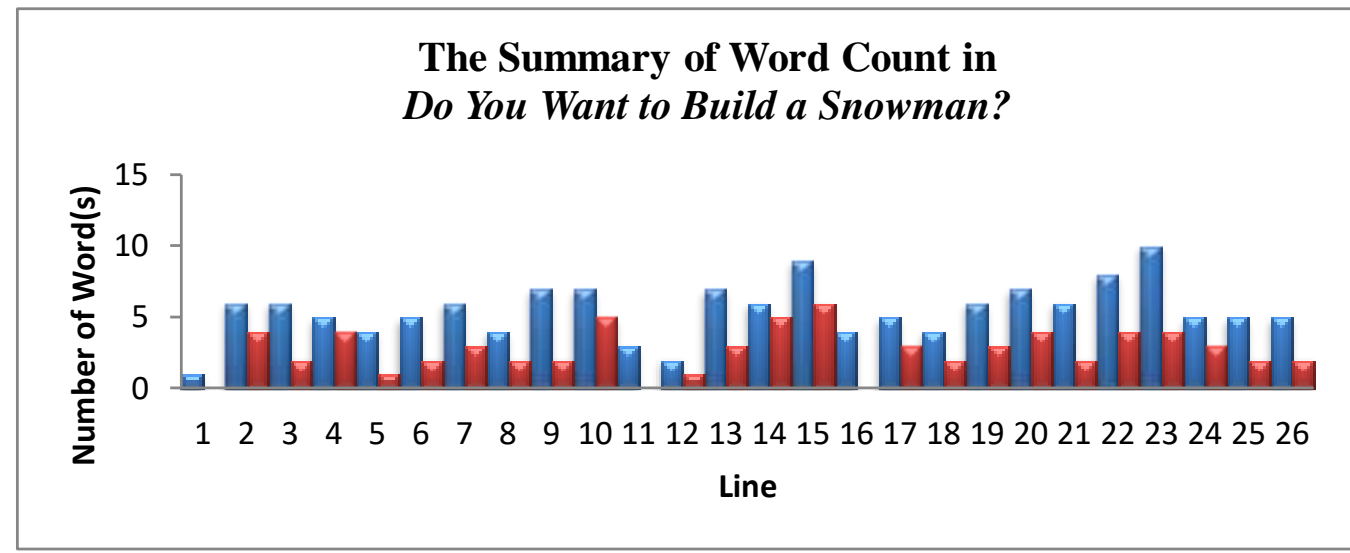

Source Line (143 words)

Target Line (69 words)

\section{Syllables vs. Words Analysis}

The strategy of syllables vs. words is a strategy that comparing the number of words and syllables in both source lines and the target lines of the song lyrics (Åkerström, 2009). The summary of syllables vs. words analysis in song "Do You Want to Build a Snowman?" is presented in Table 1.

Table 1. The Summary of Syllables vs. Words Analysis

\begin{tabular}{|c|c|c|c|c|}
\hline \multirow{2}{*}{ Line } & \multicolumn{2}{|c|}{ Source Line } & \multicolumn{2}{c|}{ Target Line } \\
\cline { 2 - 5 } & Syllables & Words & Syllables & Words \\
\hline 1 & 2 syllables & 1 word & - & - \\
\hline 2 & 8 syllables & 6 words & 8 syllables & 4 words \\
\hline 3 & 6 syllables & 6 words & 6 syllables & 2 words \\
\hline 4 & 8 syllables & 5 words & 8 syllables & 4 words \\
\hline 5 & 4 syllables & 4 words & 4 syllables & 1 word \\
\hline 6 & 6 syllables & 5 words & 6 syllables & 2 words \\
\hline 7 & 7 syllables & 6 words & 7 syllables & 3 words \\
\hline 8 & 4 syllables & 4 words & 4 syllables & 2 words \\
\hline 9 & 7 syllables & 7 words & 7 syllables & 2 words \\
\hline 10 & 8 syllables & 7 words & 9 syllables & 5 words \\
\hline 11 & 5 syllables & 3 words & - & - \\
\hline 12 & 3 syllables & 2 words & 3 syllables & 1 word \\
\hline 13 & 8 syllables & 7 words & 8 syllables & 3 words \\
\hline 14 & 10 syllables & 6 words & 10 syllables & 5 words \\
\hline 15 & 12 syllables & 9 words & 12 syllables & 6 words \\
\hline 16 & 4 syllables & 4 words & & - \\
\hline 17 & 7 syllables & 5 words & 7 syllables & 3 words \\
\hline 18 & 5 syllables & 4 words & 5 syllables & 2 words \\
\hline 19 & 7 syllables & 6 words & 7 syllables & 3 words \\
\hline 20 & 8 syllables & 7 words & 7 syllables & 4 words \\
\hline 21 & 8 syllables & 6 words & 6 syllables & 2 words \\
\hline 22 & 10 syllables & 8 words & 10 syllables & 4 words \\
\hline
\end{tabular}




\begin{tabular}{|c|c|c|c|c|}
\hline 23 & 10 syllables & 10 words & 10 syllables & 4 words \\
\hline 24 & 7 syllables & 5 words & 7 syllables & 3 words \\
\hline 25 & 5 syllables & 5 words & 4 syllables & 2 words \\
\hline 26 & 6 syllables & 5 words & 6 syllables & 2 words \\
\hline Total & $\mathbf{1 7 5}$ syllables & $\mathbf{1 4 3}$ words & $\mathbf{1 6 1}$ syllables & $\mathbf{6 9}$ words \\
\hline
\end{tabular}

Table 1 shows that the number of syllables in the source lines and target lines are slightly different in their number. On the contrary, the number of words in the target lines are significantly decreased. The analysis of syllables vs. words is illustrated through the presentation and discussion of the following one selected example.

\begin{tabular}{c|l|l} 
(2) Line & $\begin{array}{l}\text { SL: I never } \\
\text { see you } \\
\text { anymore } \\
\text { (5 words) }\end{array}$ & $\begin{array}{l}\text { TL: Ku tak } \\
\text { pernah } \\
\text { melihatmu } \\
\text { (4 words) }\end{array}$ \\
\cline { 2 - 3 } & $\begin{array}{l}\text { I/ne-ver/ } \\
\text { see/you/ } \\
\text { a-ny-more/ } \\
\text { (8 syllables) }\end{array}$ & $\begin{array}{l}\text { Ku/tak/oer- } \\
\text { nah/me-li-hat- } \\
\mathrm{mu} /\end{array}$ \\
(8 syllables)
\end{tabular}

The example of line in this syllables vs. words analysis indicates that target Line 4 appears to have fewer number of words than the source line. The fewer number of words presented by the target line do not make any change in the number of syllables because the words used in the target line contain a similar number of syllables to the source line. As the result, it can be assumed that the translator made the effort to maintain the number of syllables rather than the number of words. The practice of maintaining the number of syllables might be related to translator's decision to accommodate the lyric to the music arrangement in a way to make the lyric has the same beat.

\section{Strategic Translation Strategies Used to Translate the Lyrics}

Strategic translation strategies refer to the ways that translator used in order to overcome the challenges when translating song lyrics (Åkerström, 2009). Revealing strategic translation strategies used by the translator in translating the selected song lyrics, this study combined theories of translation strategy in translating song lyrics developed by Åkerström in 2009 and Lefevere in 1975. This study found that five strategic translation strategies out of nine strategic translation strategies have been used by the translator. The analysis of strategic translation strategies used by the translator to translate this selected song lyrics translation is presented in the following sections.

\section{Use of Paraphrases}

Paraphrase strategy is a strategy when the translator chose to maintain and present the central meaning of the source line to its closest meaning in the target line at the expense of changing the form (Åkerström, 2009). The analysis of line translated by using paraphrase strategy is illustrated through the following presentation and discussion of one selected example.

\begin{tabular}{c|l|l} 
(1) Line & $\begin{array}{l}\text { SL: I wish you } \\
\text { would tell me } \\
\text { why! }\end{array}$ & $\begin{array}{l}\text { TL: Jelaskanlah } \\
\text { mengapa! }\end{array}$
\end{tabular}

Source Line 9 'I wish you would tell me why!' seems to carry the message of expressing a desire to obtain an explanation from someone. It was translated into the phrase 'jelaskanlah mengapa!' that expresses a request for sharing information. By comparing both source line and target line in this Line 9, it can be found that they are considered to share a similar meaning which is requesting for sharing explanation. Considering what the translator did here by preserving the meaning of sharing explanation and state it in different form in target line, it can be concluded that the translator applied the strategy of paraphrasing to translate this Line 9. The different form is found because it seems also 
that the translator tried to deliver the message by using sentence construction that is easy to understand by children as the target listeners.

\section{Use of Rhymes}

Use of rhymes strategy is known as a strategy that presents a repetition of similar sound ending between a line with another line of a verse (Lefevere, 1975, cited in Aji, 2016). The analysis of line translated by using rhyme strategy is presented and discussed in the following example.

\begin{tabular}{c|l|l}
$\begin{array}{c}\text { Line } \\
7\end{array}$ & $\begin{array}{l}\text { SL: We used } \\
\text { to be best } \\
\text { buddies }\end{array}$ & $\begin{array}{l}\text { TL: Dulu kita } \\
\text { bersama }\end{array}$ \\
$\begin{array}{c}\text { Line } \\
\text { And now }\end{array}$ & Kini beda \\
Line & we're not & I wish you \\
9 & $\begin{array}{l}\text { would tell me } \\
\text { why! }\end{array}$ & Jelaskanlah \\
mengapa!
\end{tabular}

Use of rhyme strategy was identified to be applied by the translator for translating three lines, which are Line 7, Line 8, and Line 9. These aforementioned lines show that the utilization of this strategy is in line with the characteristic of triplet rhyme, which is three lines rhymed (Kuchtova, 2012), considering that three target lines appear to have a similar sound ending. Moreover, it is also identified that the triplet rhyme employed by the translator in the target lines was presented with 'A-A-A' rhyme scheme. The repetition of Indonesian vowel ' $a$ ' was applied in the target lines, as can be seen by the existence of the words 'bersama', 'beda', and 'mengapa'. Therefore, it can be concluded that the translator focused on the sound pattern of the target lines by presenting a similar sound ending in the target lines.

\section{Interpretation Strategy}

Interpretation strategy is known as a strategy that includes the translator's perspective to the translation. The message carried in the source line is developed by the translator with another possible message to the target line, depending on the context of the source line (Lefevere, 1975, cited in Aji, 2016). The analysis of line translated by using interpretation strategy is presented in the following selected example.

\begin{tabular}{c|l|l} 
(3) & Line & SL: All these \\
18 & empty rooms & TL: Aku tanpamu
\end{tabular}

Considering that the basic message of the source line refers to physical environment, the translator seemed to perceive the idea of line 'all these empty rooms' goes beyond the physical emptiness. It is found that the source line was translated into 'aku tanpamu', so that the emptiness here is interpreted as the state of being without companion. The translator seemed to interpret the idea behind the source line differently by connecting the idea to the context of the song and the situation displayed in the music video.

It is found that one of the character, Anna in the music video feels lonely because of the absence of her sister, Elsa. Thus, it can be concluded that this line was translated by using the strategy of interpretation since the target line has slightly different meaning from its source line, in which the physical thing is changed into something that related to the relationship of the characters; Anna and Elsa in the music video.

\section{Omission of Words}

Omission of words strategy is known as a strategy that eliminated any relevant information from the source line to the target line (Åkerström, 2009). The analysis of omission of words strategy is presented and discussed through the following example.

\begin{tabular}{c|l|c} 
Line & SL: Go away, & TL: - \\
11 & Anna
\end{tabular}

The example of line in this omission of words strategy shows that the message carried in the source Line 11 expresses a request to ask someone to move from one place to another place. This idea was fully eliminated by the translator to the target line. The existence of this eliminated information is in line with the characteristic of omission strategy, therefore it can be concluded that 
the translator might use the strategy of omission of words. This omission case might have relation to the part of music video of this song. It is found that this line was sung in a spoken style as conversation between characters; Elsa to Anna. Therefore, the translator chose to eliminate this spoken line in the target line of the lyric, but it exists in the music video of the song.

\section{Addition of Words}

Addition of words strategy is a strategy when the translator provides extra information in the target line of the lyrics, but the fact shows that the additional information does not exist in the source line (Åkerström, 2009). The analysis of line translated by using addition of word strategy is presented in the following example.

\begin{tabular}{c|l|l} 
Line & SL: Come on, & TL: Mainlah \\
3 & $\begin{array}{l}\text { let's go and } \\
\text { play! }\end{array}$ & denganku
\end{tabular}

The result of the translation in this Line 3 indicates that the translator possibly works by using addition of words strategy to render the source line. The source line is assumed to be having a central meaning that expresses a request to ask someone to play together, yet it does not state who is the person refers to. This idea then was translated by the translator to the target line 'mainlah denganku' by adding an extra information which is related to whom the person has to play with. This additional information can be seen by the existence of the word 'denganku' in the target line. It is considered that this additional information was provided by the translator in order to cover the unclear message of the source line, which is the subject, in a way to give a clearer information for the target listeners.

\section{Discussion}

\section{Non-Strategic Translation Strategies}

The result of the analysis under nonstrategic translation strategies indicates that there are differences between the number of words and syllables in lines of the lyrics. It is found that each target line in 26 lines of song lyrics Do you want to build a snowman? appears to have fewer number of words than the source line. The existence of this fewer number of words might be the result of translator's decisions to pay more attention on the appropriate strategies to translate lines of the lyrics, in which he aims at maintaining the basic meaning of the source line in order to present a similar idea to the target lyrics. However, the translator might also take liberties from the source meaning by incorporating different idea in the target line if there is no ideal word in the target line can fit to the music arrangement.

On the contrary, it is found that the number of syllables in the target lines is closely similar to theirs in the source lines. It possibly happens because the translator tends to use words that have similar number of syllables to the source lines. However, the closest number of syllables is suggested to be used when the translator found difficulty in finding words that have similar number of syllables to the source line. The practice of maintaining the number of syllables in target lines, either similar to or closely similar to theirs in source lines aims at making the lyrics stay fit with the music arrangement of the song. It can also be assumed that the translator employed the concept of singability to this song translation, in which he aimed at making the target lines of the lyrics singable.

\section{Strategic Translation Strategies}

The result of data analysis shows that there are five strategic translation strategies out of nine strategic translation strategies used by the translator. Those strategies are use of paraphrases, use of rhymes, interpretation strategy, omission of words, and addition of words. The overall strategic 
Figure 2. Overall Strategic Translation Strategies Analysis Result

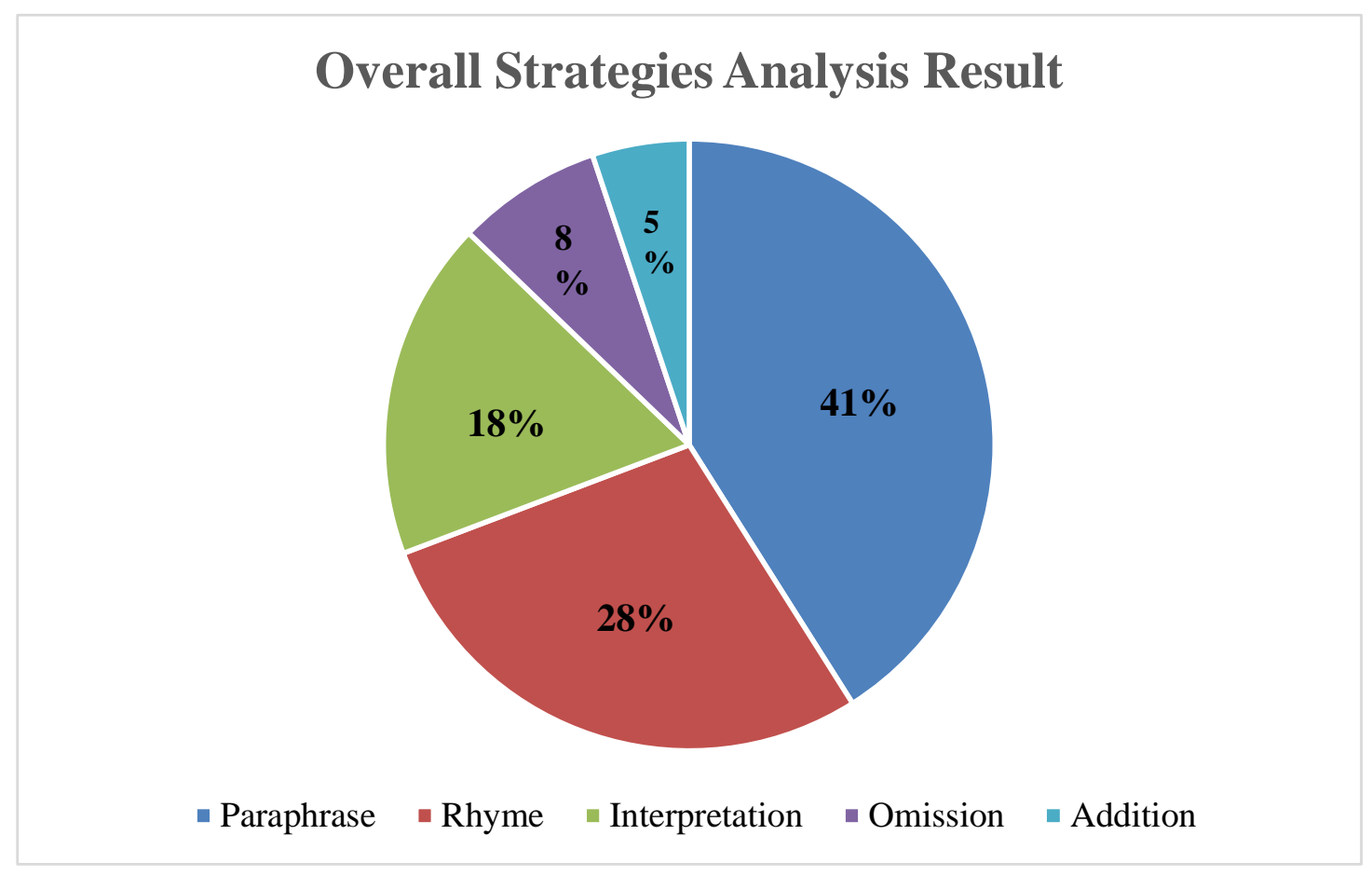

Figure 2 shows that the translator used the strategy of paraphrase most of the time (41\%). Use of rhyme is the second most used strategy $(28 \%)$. The translator also used the interpretation strategy (18\%). The next strategy is by omitting particular words or phrases from the source line (8\%). Additional of words strategy is also used by the translator (5\%).

The possible reason that might drive the translator to use strategy of paraphrase most of the time is because the translator decided to keep and present the basic meaning of the source line to its closest meaning in the target line, at the expense of changing the form in the target line. This decision is in line with one of choices the translator might take when translating song lyrics suggested by Franzon (2008), which is adapting the translation to the existing music of the song. The translator's decision to work on this choice then lead the translator not only focuses on the meaning but also to the rhythm of the music in order to make the target lyrics singable.
The utilization of rhyme strategy shows the translator not only focused on presenting similar sound ending in the target lines, but he also used words that have similar number of syllables to the source lines in orde to adapt the translation to the music arrangement of this song. Next to use of rhyme strategy, the translator also took liberties from the source meaning by incorporating different idea to the target line, as can be seen by the utilization of interpretation strategy. The translator may sacrifice the basic meaning of the source lyrics in order to maintain the singability of the target lyric.

Furthermore, the translator also utilized the strategy of omission of words, in which he eliminated some source lines that were considered as spoken lines that included in part of the lyrics. Next to omission of words strategy, additional information was also provided by the translator in the target line by using the strategy of addition of words. This strategy possibly used by the translator 
in order to provide clearer information to the target listeners and to adapt the translation of the lyrics to the music arrangement of the song.

Based on the result of the analysis regarding strategic translation strategies, it can be inferred that the translator tended to translate the lines by using certain strategies that not only focus on the meaning of the lyrics but also the musicality of the song. Therefore, the translator translated the lines by using words that have similar number of syllables to the source lyrics in order to achieve a singable song translation.

\section{Translator's Decision on Translating Do You Want to Build a Snowman? as Song for Children}

"Do you want to build a snowman?" is included as part of a collection of Disney songs so that one of its intended listeners is children. The translator is directed to pay more attention on the children understanding when he translated the original lyrics into Indonesian because children might have limited knowledge in understanding the lyrics. Based on the result of the analysis regarding the strategic translation strategies used by the translator in translating the lyrics, it is assumed that the translator realized that this song is not only listened by adults but also listened by children as its target listeners. It is the reason why the translator tends to use adaptation translation to the target lines of the lyrics in order to achieve the translation that can be easy to understand by the children as the target listeners.

The translator of this song might encounter problem of dilemma when translating the lyrics. The dilemma is whether the translator should focus on children understanding by utilizing words that are familiar for them or preserve the rhythm of the music. This is because in song translation, it cannot be denied that the singability of the translated lyrics is one of the important aspects that need to be considered by the translator in order to find a singable song translation. The translator's decision to preserve the rhythm and number of syllables seems to cost the closer adaptation to children aspects. This decisions limit the translator to come as closer as possible to the children's understanding level, familiarity to the words, and ability to catch the meaning.

\section{Conclusion}

There are two main conclusions to be drawn from the result of the analysis. The first conclusion is related to the non-strategic translation strategy. It is found that the translator tends to translate lines of the lyrics with a fewer number of words because he might translate the lines by maintaining or changing the central meaning of the source lines. In terms of number of syllables, source lines and target lines share the similar number. The translator tends to translate the lines by using words that contain similar number of syllables or closely similar to the source lines in order to find a singable song translation.

Regarding what strategic translation strategies used by the translator, it is found that five strategic translation strategies have been used by the translator, they are use of paraphrases, use of rhymes, interpretation strategy, omission of words, and addition of words. It is probably because the translator aims at adapting the translation to the music arrangement of the song and achieve a singable song translation. This study also brought by-product result that is the translator did not use four other strategic translation strategies in translating lines of the lyrics. Those strategic translation strategies are literal translation, word for word translation, use of metaphors, and use of English words in the translation.

\section{References}

Aji, Krisna Bayu. (2016). Song Translation Analysis of Five Disney Movie's English Songs. Yogyakarta: Yogyakarta State University. 
Åkerström, J. (2009). Translating Song Lyrics: A Study of the Translation of the Three Musicals by Benny Andersson and Björn Ulvaeus. Sweden: Södertörn University.

Fraenkel, Jack. R., Wallen, Norman. E., \& Hyun, Helen. H. (1993). How to Design and Evaluate Research in Education. The McGraw-Hill, $8^{\text {th }}$ Ed. New York: McGrawHill.

Franzon, Johan. (2008). "Choices in Song Translation: Singability in Print, Subtitles, and Sung Performances." Article in Translator, 14(2), 373-399.

Kales, D. Translation and Adaptation of English Song Lyrics into Turkish between 19651980: Analysis Within The Framework of Polysystem Theory and Song Translation Strategies. Ankara: Hacettepe University, 2015.

Klingberg, G. (1986). Children's Fiction in the Hands of the Translators. Lund: CKW Gleerup.

Kuchtová, Eva. (2012). Rhyme in Czech Translation of English Romantic Poetry. Brno: Masaryk University.

Maulana, Winny. R. (2016). Lyrics Translation Strategies of Terlalu Manis Translated Into Too Sweet Too Forget. Semarang: Dian Nuswantoro University.

Rurangwa, Narcisse. (2005). "Translating Rwandan Folktales into English: A Culture-Based Analysis." Johannesburg: University of the Witwatersrand.

Siitonen, M. L. (2014). Subtitling The Songs in The Eurovision Song Contest. Finland: University of Eastern Finland.

Stephenson, Jean. (2014). "Quizás, quizás, quizás": Translators' Dilemmas and Solutions When Translating Spanish Songs into English. Doctora. Spain: University of Granada.
Stolze, Radegundis. (2003). "Translating for Children - World View or Pedagogics?" Meta, 48(1-2), 208-221. 